\title{
Ciência da Informação e História: os estudos históricos nos progra- mas de pós-graduação brasileiros da área de Ciência da Informação
}

\author{
Information Science and History: the historical studies in Brazilian graduate programs in \\ the Information Science area
}

\author{
Leonardo Gonçalves Silva \\ Mestre em Ciência da Informação \\ Universidade de São Paulo \\ leonardo656@hotmail.com \\ Lúcia Maciel Barbosa de Oliveira \\ Doutora em Ciência da Informação \\ Universidade de São Paulo \\ mbol.lucia@gmail.com
}

\begin{abstract}
Resumo
Busca na literatura as relações entre Ciência da Informação e História. Verificar se os pesquisadores brasileiros da área da Ciência da Informação com formação em História realizam pesquisas históricas sobre o tema da informação. Revisão de literatura e análise dos currículos Lattes dos docentes com formação em História dos programas de pós-graduação da área de Ciência da Informação. A análise mostrou que mesmo havendo uma quantidade razoável de docentes com formação em História atuando nesses programas, são poucos os que realizam pesquisas históricas de contextos informacionais. As pesquisas históricas dentro da Ciência da Informação ainda são poucas e ainda necessitam ser mais realizadas. A realização de tais pesquisas podem enriquecer a área e trazer a ela novos tópicos de discussão e uma compreensão adensada da informação em diferentes contextos.
\end{abstract}

\section{Palavras-chave}

Ciência da Informação. História. Interdisciplinaridade. Brasil. Programas de Pós-Graduação.

\begin{abstract}
Search the literature for the relations between Information Science and History. To verify if the Brazilian researchers of the area of Information Science with formation in History realize historical investigations on the subject of the information. Literature review and analysis of curriculum Lattes of teachers with a background in History who work in graduate programs in the area of Information Science. The analysis showed that even with a reasonable amount of teachers with degrees in History working in these programs, there are few who perform historical research of informational contexts. Historical research within Information Science is still few and still needs to be done more. Such research can enrich the area and bring to it new discussion topics and a rich understanding of information in different contexts.
\end{abstract}

Keywords

Information Science. History. Interdisciplinarity. Brazil. Graduate Programs. 


\section{INTRODUÇÃO}

Muito se fala sobre o caráter indisciplinar da Ciência da Informação. É inegável que ela dialoga com as mais diversas disciplinas, pois todas as áreas do conhecimento, de uma forma ou de outra, lidam com informação. É comum encontrar na literatura que a Ciência da Informação dialoga com diversas áreas, como a Administração, a Linguística e a Educação, e diversos estudos vêm ressaltando as relações da Ciência da Informação com essas e outras disciplinas científicas. No entanto, poucas menções aparecem na literatura sobre as ligações entre Ciência da Informação e História.

Este trabalho apresenta reflexões sobre a interdisciplinaridade na Ciência da Informação, mas de modo mais específico, buscou-se na literatura as relações entre a Ciência da Informação e a História. Sendo a História a ciência que se ocupa da compreensão e análise crítica dos eventos do passado, supõe-se que seus métodos e teorias podem colaborar com a Ciência da Informação nos estudos de antigos objetos e contextos informacionais.

A investigação aqui realizada procurou verificar se há diálogo entre as duas disciplinas nos programas de pós-graduação brasileiros da área de Ciência da Informação. Visando ter uma amostragem que permitisse essa análise, foram consultados e analisados os currículos dos docentes com formação em História e que atuam nesses programas. Buscava-se resposta para a seguinte pergunta de pesquisa: tais pesquisadores utilizam a sua formação para realizar estudos históricos da informação dentro da Ciência da Informação? Para se chegar a uma resposta foi necessária, além da análise dos currículos, uma compreensão geral da interdisciplinaridade na Ciência da Informação e uma busca na literatura sobre as relações entre Ciência da Informação e História.

\section{CIÊNCIA DA INFORMAÇÃO E INTERDISCIPLINARIDADE}

Estabelecida como área do conhecimento no decorrer da segunda metade do século XX, a Ciência da Informação surge com a necessidade de se lidar com o volume cada vez maior de informações e, sobretudo, recuperá-las. Para tal fim, o campo informacional recebeu, desde seu início, contribuições das mais diversas áreas do conhecimento.

A questão sobre quais disciplinas estão nos primórdios da Ciência da Informação, e as que foram compondo o seu arcabouço teórico, varia de acordo com os diversos autores da área. Le Coadic (2004, p. 12), por exemplo, aponta como primeiras disciplinas "a biblioteconomia, a museoconomia, a documentação e o jornalismo". Oliveira $(2005$, p. 13), por outro lado, considera que a gênese e o desenvolvimento da Ciência da Informação se encontram em duas disciplinas, a Documentação e a Recuperação da Informação. Autores como Mikhailov, Chernyi e Gilyarevskyi, da antiga União Soviética, apresentaram, na década de 1960, a Ciência da Informação (na União Soviética denominada como Informática) como tendo importantes relações com a Semiótica, a Psicologia e a Biblioteconomia (PINHEIRO, 1999, p. 161). As mais diversas abordagens sobre a interdisciplinaridade na Ciência da Informação são apresentadas no estudo de Pinheiro (1999), que cita várias disciplinas que comumente são apontadas como tendo relações com a Ciência da Informação.

Mesmo com visões diferentes acerca das contribuições de cada disciplina para a área, a interdisciplinaridade é frequentemente lembrada como uma característica da Ciência da Informação, embora concorde-se com Smit e Tálamo quando afirmam que o "caráter interdisciplinar da $\mathrm{Cl}$ é mais objeto de afirmação do que de discussão ou explicação" (SMIT; TÁLAMO, 2007, p. 35). 
Antes de discutir os aspectos interdisciplinares na Ciência da Informação, é essencial ter clareza do que se entende por interdisciplinaridade e seus conceitos correlatos, como pluri, multi e transdisciplinaridade, pois todos eles evocam um grau diferente de diálogo disciplinar. Ainda que tais conceitos não possuam uma definição universal, podendo variar entre os autores. Pombo (1993, p. 12) define a pluridisciplinaridade como a associação entre disciplinas, sem que haja alterações na forma de ensino das mesmas. A transdisciplinaridade é vista pela autora como "o nível máximo de integração disciplinar" (POMBO, 1993, p. 13), na qual ocorre a unificação de disciplinas, com base em fundamentos comuns. A multidisciplinaridade é a "justaposição de disciplinas diversas, às vezes sem relação aparente entre elas" (POMBO, 1993, p. 11), contudo, a autora concorda que a diferença entre pluri e multidisciplinaridade é tênue. Os prefixos destas palavras carregam significado: enquanto pluri evoca o significado de vários, multi indica muitos.

Já a interdisciplinaridade, deve ser pensada como "mais do que a pluridisciplinaridade e menos do que a transdisciplinaridade" (POMBO, 1993, p. 11, grifo da autora), por isso, é definida como:

[...] qualquer forma de combinação entre duas ou mais disciplinas com vista à compreensão de um objecto a partir da confluência de pontos de vista diferentes e tendo como objectivo final a elaboração de uma síntese relativamente ao objecto comum. (POMBO, 1993, p. 13, grifos da autora).

Pinheiro (1999) atesta que diversos autores desde a década de 1960 vêm apontando o caráter interdisciplinar da Ciência da Informação e as suas relações com as mais diferentes disciplinas, mas cabe refletir até que ponto tais relações são concretas, pois:

Relações interdisciplinares são relações de troca teórica e metodológica e para que tal ocorra, é imprescindível clareza para identificar, entre as disciplinas envolvidas, onde se dá o encontro ou a interseção de duas áreas de conhecimento [...] (PINHEIRO, 1999, p. 164).

No caso da Ciência da Informação, é esperado que conceitos de outras áreas sejam utilizados pelo campo, pois as mais diversas áreas do conhecimento lidam com informação. Sendo a informação algo complexo, não é possível que seus problemas possam ser resolvidos por uma única disciplina (SANTOS; RODRIGUES, 2013, p. 345). Contudo, mais do que receber conceitos de outras áreas, a interdisciplinaridade exige relações de troca, onde possa haver a transferência de conhecimento para outros campos. Nesse sentido, alguns autores concordam que a Ciência da Informação não vem de fato exercendo a interdisciplinaridade, uma vez que mais recebe do que transfere conhecimento para outras áreas (PINHEIRO, 1999; SMIT; TÁLAMO, 2007).

\section{CIÊNCIA DA INFORMAÇÃO E HISTÓRIA}

Em texto publicado na década de 1990, Pinheiro (1999, p. 174) apresenta um diagrama no qual são identificadas algumas disciplinas que, segundo a autora, possuem relações diretas com a Ciência da Informação. O diagrama mostra doze disciplinas trabalhadas dentro da Ciência da Informação (ex.: Comunicação Científica e Tecnológica, Economia da Informação, etc.), e as respectivas áreas do conhecimento que estão relacionadas com tais disciplinas (ex.: em Economia da Informação são apresentadas as áreas de Economia, Estatística e Administração), sendo que diversas disciplinas aparecem em mais de um campo de 
estudo (ex.: Estatística também possui relações com as disciplinas de Administração de Serviços de Informação e com a Biblioteconomia).

A História aparece somente uma vez no diagrama como área interdisciplinar da disciplina Informação, cultura e sociedade, juntamente com a Biblioteconomia, a Museologia, a Arquivologia, a Sociologia, a Educação e a Antropologia. O que sugere, ao menos em teoria, que algum tipo de relação existe entre as duas disciplinas.

Primeiramente, é preciso ressaltar que, quando este trabalho busca as relações entre as duas disciplinas, não se refere a estudos que apresentam a história da Ciência da Informação como campo de conhecimento ou de suas disciplinas correlatas, como a Biblioteconomia e a Documentação, pois diversos são os estudos que relatam o percurso histórico de consolidação da área como campo científico e acadêmico. Dentre os trabalhos dessa linha podem ser citados, por exemplo, os de Buckland (1997), Rayward (1997), Hahn e Buckland (1998) e Barreto (2008). Há inclusive uma bibliografia da História da Ciência da Informação, que abrange o período entre 1900 e 2012 (WILLIAMS, 2012), com ênfase nas publicações produzidas na América do Norte.

O que se investiga é se na Ciência da Informação são realizados estudos históricos da informação e de contextos informacionais, sem se limitar à história da Ciência da Informação como disciplina, afinal, conforme aponta Araújo (2014, p. 2):

Qualquer tentativa de fazer um histórico da Ciência da Informação precisa necessariamente recuar no tempo até a ação humana de produzir registros materiais de seus conhecimentos - ação essa que está na origem mesma da formação da cultura humana. É com essa ação que surgem, num primeiro momento, os documentos (aqui entendidos em sentido muito amplo, como manuscritos literários, registros administrativos, selos, mapas, esculturas, etc.), instituições dedicadas a salvaguardá-los (que deram origem ao que atualmente são os arquivos, as bibliotecas e os museus) e regras para organizar esses documentos.

A consolidação da Ciência da Informação como disciplina é mais recente, contudo, as preocupações com a informação e seus suportes e instituições é muito anterior. Por isso, não caberia também à Ciência da Informação, mesmo sendo recente como disciplina, a compreensão dos contextos informacionais do passado? Pois, pode-se pensar que:

At one extreme, almost everything could be argued to be information. The history of the universe would then become the history of information processing. The history of humanity becomes the history of information processing within a social context. If everything is information, then not only is all history the history of information, all scientific work is information science. (RAYWARD, 1998, p. 8).

Tal visão, mesmo que extrema, não deixa de ser realista, afinal, a humanidade sempre produziu e transmitiu informações, mesmo antes da invenção da escrita. Sendo a Ciência da Informação a disciplina que busca entender os processos de geração, organização, difusão, apropriação e uso da informação, defende-se neste trabalho que a Ciência da Informação pode e deve buscar entender como tais processos se davam em tempos passados, ou seja, realizar pesquisas históricas sobre a informação. Nestas pesquisas se incluiriam certamente as histórias dos livros e das bibliotecas, mas não se limitariam a elas.

Admite-se, entretanto, que os profissionais formados nos cursos de Ciência da Informação nem sempre recebem a formação da teoria e dos métodos da História para a realização de estudos históricos. Acredita-se que, se encorajados, tais estudos poderiam trazer novas contribuições à área. Neste aspecto concorda Crippa (2010, p. 104), ao dizer que: 
O sujeito oriundo do curriculum mínimo necessário à formação na área de Ciência da Informação não possui, necessariamente, as ferramentas metodológicas de uma Teoria da História que Ihes permitam articular novas trajetórias reflexivas sobre o próprio campo. Por outro lado, o olhar de escolas históricas voltadas para uma pesquisa indiciária, como propõe Carlo Ginzburg, ou para os estudos de uma História Cultural, como no caso de Chartier, Darnton ou Burke, apresentam perspectivas renovadas em estudos históricos sobre as atividades bibliográficas e de catalogação, propondo abordagens inéditas de análise dos sistemas de produção, seleção, organização e mediação cultural de objetos já amplamente estudados: os livros, as coleções, os registros materiais que, em algum momento, se tornaram dignos de serem preservados e disseminados para a constituição da ciência moderna.

Estudos como os de Peter Burke, citados por Crippa (2010), se encaixam no que o autor chama de Sociologia do conhecimento, e os dois volumes de sua obra Uma história social do conhecimento (BURKE 2003, 2012) narram qual foi o papel do conhecimento e os seus percursos (incluindo, obviamente, a informação registrada em diferentes suportes) junto aos diversos grupos sociais em determinado tempo histórico. Em suas palavras, "uma história social do conhecimento precisa, evidentemente, abordar as maneiras como os diferentes grupos adquirem, processam, difundem e utilizam o conhecimento [...]" (BURKE, 2012, p. 21). Não é arriscado supor que estudos com esta proposta podem se vincular sem muitas dificuldades às investigações da Ciência da Informação. No Brasil, alguns trabalhos recentes seguem uma linha semelhante, como os de Araújo (2015) e Crippa (2015), que abordam o tema da Bibliografia, e o de Silva e Silva (2015), que faz uma análise histórica sobre um inventário bibliográfico.

O pesquisador americano Lawrence J. McCrank, que lecionou Biblioteconomia e Ciência da Informação na Chicago State University, e que possui trabalhos sobre as relações entre Ciência da Informação e História (MCCRANK, 1995, 2002), chegou a propor em um deles uma nova disciplina, ou campo de atuação da Ciência da Informação, denominado Historical Information Science, que para ele:

The neologism "Historical Information Science" is used here as more than simply an interdisciplinary combination of History and Information Science (which is also seen as a Social Science, distinct from Computer Science). The whole, it will be argued, is greater than the sum of its parts in this case. (MCCRANK, 2002, p. 16).

É possível a aproximação entre as duas áreas, sobretudo, quando se pensa que ambas lidam com fontes/documentos. A História se utiliza das fontes materiais (mas não só delas) para o estudo dos contextos históricos. A Ciência da Informação utiliza suas ferramentas para organizar e possibilitar a recuperação dessas mesmas fontes.

\section{METODOLOGIA}

O objetivo da pesquisa foi verificar se existem, na prática, relações entre Ciência da Informação e História. Mais especificamente, buscou-se levantar se os pesquisadores brasileiros da área da Ciência da Informação realizam estudos históricos da informação. Para tanta, utilizou-se amostragem originária da análise dos currículos dos docentes dos programas brasileiros de pós-graduação em Ciência da Informação que possuíssem formação em História.

A escolha deste escopo foi motivada pelos seguintes questionamentos: há pesquisadores com formação em História nos programas de Ciência da Informação? Esses pesquisa- 
dores realizam pesquisas históricas sobre informação ou sobre a própria história da Ciência da Informação? A presença desses docentes contribui para que haja uma verdadeira interdisciplinaridade entre a Ciência da Informação e a História?

Dividida em três etapas, a pesquisa foi realizada nas duas primeiras semanas de julho de 2016.

A primeira etapa consistiu no levantamento de quais eram os programas stricto sensu da área de Ciência da Informação devidamente ativos e registrados na Coordenação de Aperfeiçoamento de Pessoal de Nível Superior (CAPES) naquele momento. Utilizando a Plataforma Sucupira da CAPES ${ }^{1}$, que concentra informações sobre toda a pós-graduação stricto sensu do Brasil, foram encontrados os programas da área do conhecimento Ciência da Informação, que se encontrava dentro da área de avaliação Ciências Sociais Aplicadas $I^{2}$. No total, foram recuperados 20 programas de 18 instituições diferentes, entre mestrados, doutorados e mestrados profissionais. Duas instituições possuíam mais de um programa na área (Universidade Federal de Minas Gerais (UFMG): mestrado e doutorado em Ciência da Informação e mestrado e doutorado em Gestão e Organização do Conhecimento; Universidade Federal do Estado do Rio de Janeiro (UNIRIO): mestrado profissional em Biblioteconomia e mestrado profissional em Gestão de Documentos e Arquivos).

Foi então criada uma tabela, onde foram colocados os dados dos programas encontrados. A tabela foi dividida em Unidade da Federação, Instituições (nome da instituição), Programa(s) (nome do programa) e Categoria (mestrado (M), doutorado (D) ou mestrado profissional (MP)). Após este trabalho, foram acessados os endereços eletrônicos de todos os programas. Nesta fase foram buscadas as respectivas Áreas de concentração e Linhas de pesquisa dos programas. Estas informações também foram incluídas na tabela e utilizadas na análise dos dados.

A segunda etapa consistiu no levantamento dos docentes dos programas que tivessem alguma formação acadêmica em História. A escolha por este escopo não queria supor que docentes com formações diferentes não possam fazer, ou não façam, pesquisas históricas dentro da Ciência da Informação, mas era necessário o refinamento para uma melhor análise dos dados. Para a busca foram utilizadas as páginas eletrônicas dos programas, que geralmente disponibilizam a lista dos docentes já com o link para a Plataforma Lattes $^{3}$, onde se localizam os respectivos currículos. A exceção ocorreu com o site do programa da Universidade Federal da Paraíba (UFPB), cujo site estava bastante incompleto e não apresentava, entre outras coisas, os docentes credenciados. Neste caso, recorreu-se a Plataforma Sucupira, que também contém a listagem dos docentes de cada programa, porém, sem fornecer o link para o Currículo Lattes.

Em cada acesso ao Currículo Lattes de um docente, quando se observava a presença de alguma formação acadêmica em História (seja graduação, mestrado ou doutorado), seu nome era incluído em uma segunda tabela, elaborada para esta etapa. Nessa tabela foi descrita a respectiva formação do docente, sendo composta dos seguintes campos: Instituição, Nome(s) do(s) docente(s), Formação (se graduação, mestrado e/ou doutorado em História), Descrição da formação e Total de docentes (do programa com formação em História).

\footnotetext{
${ }^{1}$ https://sucupira.capes.gov.br/sucupira/

${ }^{2}$ Atualmente não existe mais a área de avaliação denominada Ciências Sociais Aplicadas I. Os programas de Ciência da Informação estão dentro de uma nova área denominada Comunicação e Informação, que abrange, além da $\mathrm{Cl}$, as áreas de Comunicação, Desenho Industrial e Museologia.

${ }^{3}$ http://buscatextual.cnpq.br/buscatextual/busca.do?metodo=apresentar
} 
Ressalta-se que o levantamento buscou docentes sem levar em conta o grau de vinculação ao programa, ou seja, independentemente do docente ser permanente, colaborador ou visitante.

A terceira etapa consistiu na análise dos dados propriamente dita, na qual os currículos dos docentes levantados foram novamente acessados, para uma observação mais detaIhada de sua produção e assuntos de pesquisa.

\section{ANÁLISE DOS DADOS}

A busca pelos currículos de docentes com alguma formação em História recuperou 47 docentes, sendo que quatro deles atuavam em mais de um programa. No total de 20 programas, 14 apresentaram um ou mais docentes. Seis não apresentaram nenhum docente com essa formação, sendo eles os das seguintes instituições: Universidade Federal do Cariri (UFCA), Universidade Federal de Minas Gerais (UFMG, programa de Gestão e Organização do Conhecimento), Universidade Federal da Paraíba (UFPB), Universidade Estadual de Londrina (UEL), Universidade Federal do Rio Grande do Norte (UFRN) e Universidade Federal de São Carlos (UFSCAR).

Ressalta-se que nenhum programa apresenta área de concentração ou linha de pesquisa em estudos históricos, ou algo do gênero. Alguns apresentam em suas áreas ou linhas de pesquisa as palavras Cultura e/ou Memória (Memória: UFCA, UFPB, Universidade Federal de Pernambuco (UFPE), Fundação Casa de Rui Barbosa (FCRB), Universidade do Estado de Santa Catarina (UDESC); Cultura: UFCA, UFMG (programa de Ciência da Informação), UNIRIO (programa de Biblioteconomia), Universidade Federal Fluminense (UFF), Universidade de São Paulo (USP)) que poderiam abranger, supõem-se, pesquisas de caráter histórico. A seguir são comentados cada um dos programas que possuem docentes com as características buscadas.

A Universidade Federal da Bahia (UFBA) possui quatro docentes, sendo que um deles integra também outro programa (UNIRIO). Três com graduação em História e mestrado e doutorado em outras áreas, e um com mestrado em História e graduação e doutorado em outras áreas. Três dos docentes estão ligados ao campo da Arquivologia e/ou Audiovisual, sem ligação aparente com pesquisas de cunho histórico. Um docente coordena um projeto de pesquisa que estuda a leitura no século XIX, mas o foco de sua produção e atuação não parece estar em estudos históricos.

A Universidade Federal do Ceará (UFC) possui um docente com mestrado em História, e que também atua em outro programa (Universidade Estadual Paulista "Júlio de Mesquita Filho" (UNESP)). Realizou algumas produções sobre Memória.

A Universidade de Brasília (UNB) tem cinco docentes, sendo três deles com toda a formação em História, um com graduação e mestrado e outro com graduação e doutorado. As pesquisas desses docentes abrangem diversos temas: Museologia, documentação fotográfica, política de informação, patrimônio cultural, Arquivologia e arquivos, sendo que as últimas são predominantes. Nenhum docente aparenta ter a produção focada em pesquisas históricas, contudo, um docente possui pelo menos dois artigos do ramo (um que envolve a história da Documentação e outro a da Biblioteca Nacional) e já orientou dissertações e teses do gênero.

Na Universidade Federal de Minas Gerais (UFMG), há no programa de Ciência da Informação seis docentes, três com formação completa em História, um com graduação, outro com graduação e mestrado, outro com graduação e doutorado. Os temas de pesquisa desses 
docentes também são variados, sendo possível identificar: Memória, Direitos Humanos, Museologia e Museus, patrimônio histórico, história da música, e, principalmente, Arquivologia e arquivos. Nenhum aparenta fazer pesquisas históricas sobre o campo informacional.

A Universidade Federal de Pernambuco (UFPE) tem dois docentes com formação em História: um com mestrado e doutorado, outro com doutorado. Um dos docentes trabalha com pesquisas históricas da informação: além de ter no doutorado realizado uma pesquisa de teor histórico da informação, possui diversos trabalhos na temática.

Na Fundação Casa de Rui Barbosa (FCRB), dos seis docentes encontrados com formação em História, quatro possuem toda a formação acadêmica, e dois, graduação e doutorado. Dois deles atuam também em outro programa (UFF). As pesquisas dos docentes abrangem temáticas variadas, como gestão de documentos, diplomática, escravidão, política cultural, Arquivologia e arquivos e história cultural. Boa parte deles realiza pesquisas históricas, mas nenhum parece ter como foco as pesquisas históricas no campo informacional.

$\mathrm{Na}$ Universidade Federal do Estado do Rio de Janeiro (UNIRIO), o programa de Biblioteconomia possui um docente com doutorado em História das Ciências, mas que não tem como foco pesquisas históricas da informação. Já o programa de Gestão de Documentos e Arquivos há sete professores, sendo que um deles também faz parte de outro programa (UFBA). Dois deles com toda a formação em História, três somente com a graduação, um com graduação e doutorado e outro com mestrado. As pesquisas dos docentes são focadas na Arquivologia e nos arquivos. Outros temas que apareceram: censura, memória, informação pública, fotografia, gestão documental, etc.

$\mathrm{Na}$ Universidade Federal do Rio de Janeiro - Instituto Brasileiro de Informação em Ciência e Tecnologia (UFRJ-IBICT), três docentes possuem alguma formação em História, sendo dois com graduação e um com mestrado e doutorado. As pesquisas desenvolvidas por esses docentes abrangem temas como bibliotecas comunitárias, memória e política.

A Universidade Federal Fluminense (UFF) tem quatro docentes, sendo dois com formação completa em História, um com graduação e doutorado, e outro somente com graduação. Dois docentes pertencem também a outro programa (FCRB). Suas pesquisas focam, sobretudo, a Arquivologia e os arquivos.

A Universidade do Estado de Santa Catarina (UDESC) possui um docente com doutorado em História. Suas pesquisam focam a área da Educação.

A Universidade Federal de Santa Catarina (UFSC) possui um docente com mestrado e doutorado em História. $O$ foco de suas pesquisas está na área de História e meio ambiente.

A Universidade de São Paulo (USP) possui dois docentes, um com graduação, outro com graduação e doutorado. O primeiro docente exerce suas pesquisas na área de política cultural. As pesquisas do segundo estão no campo da Memória, mas possui algumas produções no campo da história da organização do conhecimento, sobretudo da Bibliografia.

A Universidade Estadual Paulista "Júlio de Mesquita Filho" (UNESP) apresenta oito docentes, sendo dois com formação completa em História, dois com a graduação, um com mestrado, um com doutorado, um com graduação e doutorado e um com graduação e mestrado. Um dos docentes integra outro programa (UFC). As pesquisas dos docentes abrangem as mais diversas temáticas, como cultura organizacional, memória, produção documental e acervos audiovisuais, com predomínio das pesquisas sobre Arquivologia e arquivos. Nenhum deles apresentou produção focada em estudos históricos da informação.

O Quadro 1 resume os dados levantados. O acesso ao currículo dos docentes confirmou que a área é mesmo formada por profissionais das mais diversas formações, como Medicina, Estatística, Letras, Pedagogia, Direito, Administração, Filosofia, Economia, etc. O que 
provavelmente une conhecimentos tão diversificados em uma única área são as preocupações com os fenômenos informacionais. Os pesquisadores com formação em História também estão presentes na área: dos 20 programas apenas seis (30\%) não apresentaram docentes com essa formação. Nos 14 que possuem (70\%), o número de docentes variou: alguns apresentaram apenas um docente, como os programas da UFC, da UDESC e da UFSC. Já o da UNESP, o que apresentou maior número, possui oito docentes. Contudo, o que possui a maior porcentagem de docentes é o programa de Gestão de Documentos e Arquivos da UNIRIO, onde $47 \%$ dos docentes têm formação histórica.

Quadro 1 - Números de docentes por programa

\begin{tabular}{|c|c|c|c|}
\hline \multirow[b]{2}{*}{ Instituição } & \multicolumn{3}{|c|}{ Docentes por programa } \\
\hline & Total $f(x)$ & $\begin{array}{l}\text { Com formação } \\
\text { em História } f(x)\end{array}$ & $\begin{array}{l}\text { Com formação } \\
\text { em História } f(\%)\end{array}$ \\
\hline FCRB & 22 & 6 & $27 \%$ \\
\hline UDESC & 17 & 1 & $6 \%$ \\
\hline UEL & 12 & 0 & $0 \%$ \\
\hline UFBA & 18 & 4 & $22 \%$ \\
\hline UFC & 16 & 1 & $6 \%$ \\
\hline UFCA & 16 & 0 & $0 \%$ \\
\hline UFF & 15 & 4 & $27 \%$ \\
\hline UFMG (Ciência da Informação) & 21 & 6 & $29 \%$ \\
\hline UFMG (Gestão e Organização do Conhecimento) & 16 & 0 & $0 \%$ \\
\hline UFPB & 21 & 0 & $0 \%$ \\
\hline UFPE & 15 & 2 & $13 \%$ \\
\hline UFRJ-IBICT & 26 & 3 & $12 \%$ \\
\hline UFRN & 10 & 0 & $0 \%$ \\
\hline UFSC & 22 & 1 & $5 \%$ \\
\hline UFSCAR & 10 & 0 & $0 \%$ \\
\hline UNB & 33 & 5 & $15 \%$ \\
\hline UNESP & 33 & 8 & $24 \%$ \\
\hline UNIRIO (Arquivologia) & 15 & 7 & $47 \%$ \\
\hline UNIRIO (Biblioteconomia) & 26 & 1 & $4 \%$ \\
\hline USP & 21 & 2 & $10 \%$ \\
\hline
\end{tabular}

Fonte: dados da pesquisa (2016).

O grau de formação em História também variou bastante entre esses docentes: muitos têm toda a formação acadêmica (graduação, mestrado e doutorado) na área, outros apenas a graduação, sendo as demais formações em outras áreas das Ciências Humanas, por exemplo.

A análise do currículo dos docentes mostrou que, diferentemente do que a formação em História possa sugerir, poucos deles realizam pesquisas históricas da informação, ou mesmo sobre a história da Ciência da Informação. Apenas um docente, da UFPE, parece focar suas pesquisas nessa linha. Um da USP possui algumas produções relacionadas, e outro da UNB tem algumas produções na linha, porém, sem focar nela suas produções e pesquisas. 


\section{CONSIDERAÇÕES FINAIS}

Esta pesquisa objetivou buscar elementos de interdisciplinaridade entre Ciência da Informação e História. Para isso, foi necessário, em primeiro lugar, o entendimento do próprio conceito de interdisciplinaridade e de outros correlacionados. Também foi buscado o que há na literatura sobre as relações entre Ciência da Informação e História.

Para verificar se tais relações se dão no contexto da Ciência da Informação brasileira, foram analisados os currículos dos docentes com formação em História que atuam em programas da área de Ciência da Informação. O objetivo era verificar se estes pesquisadores realizam pesquisas históricas sobre contextos informacionais. Mesmo que em 2016, ano em que foi realizado o levantamento e a análise dos dados, houvesse um número considerável de docentes (47), a análise dos currículos mostrou que apenas um deles parecia concentrar as suas pesquisas nessa linha. Isso não significa que os outros docentes não coloquem em diálogo as duas áreas, pois muitos deles atuam em campos que possuem afinidades com a História, como a Memória e a Arquivologia. Contudo, fica em aberto a questão se está mesmo havendo relações interdisciplinares entre as duas áreas, pois, conforme mostrou a literatura, as relações interdisciplinares são relações de troca entre as áreas. A Ciência da Informação já mostrou que recebe conhecimentos vindos da História, contudo, ainda faltam estudos que confirmem ou não se o contrário também ocorre. É necessária ainda a compreensão de como os estudos históricos na Ciência da Informação poderiam dialogar com a História.

O que se defende neste trabalho é que a Ciência da Informação realize mais estudos históricos de contextos informacionais, o que resultaria em novos tópicos enriquecedores de discussão para o campo. Foi observado que pesquisas nesse sentido nos programas brasileiros ainda são tímidas e necessitam ser mais realizadas. A observação das áreas de concentração e linhas de pesquisa dos programas mostrou que nenhum deles possui foco em estudos históricos. Acredita-se também que a compreensão do passado pelo viés da informação pode ser útil mesmo nas discussões de temáticas informacionais contemporâneas. Os pesquisadores da Ciência da Informação que se interessarem em realizar pesquisas no tema, tendo ou não formação em História, poderão se deparar com um rico e promissor campo de pesquisa. Ressalta-se, entretanto, que o aumento da quantidade desses estudos não resultará por si só no aumento das relações interdisciplinares entre Ciência da Informação e História. $\mathrm{O}$ enriquecimento mútuo entre as áreas só deve ocorrer caso haja verdadeiro compartiIhamento e cooperação entre seus pesquisadores.

\section{REFERÊNCIAS}

ARAÚJO, A. V. F. Pioneirismo bibliográfico em um polímeta do séc. XVI: Conrad Gesner. Informação \& Informação, Londrina v. 20, n. 2, p. 118-142, ago. 2015. Disponível em: http://www.uel.br/revistas/uel/index.php/informacao/article/view/23127. Acesso em: 22 maio 2019.

ARAÚJO, C. A. Á. O que é Ciência da Informação?. Informação \& Informação, Londrina, v. 19, n. 1, p. 01-30, jan./abr. 2014. Disponível em: http://www.uel.br/revistas/uel/index.php/informacao/article/view/15958/14205. Acesso em: 22 maio 2019. 
BARRETO, A. Uma quase história da ciência da informação. DataGramaZero, v. 9, n. 2, 2008. Disponível em: http://eprints.rclis.org/17637/1/DataGramaZero\%20\%20Revista\%20de\%20Ci\%C3\%AAncia\%20da\%20Informa\%C3\%A7\%C3\%A3o\%20\%20Artigo\%2001 Aldo.pdf. Acesso em: 22 mai. 2019.

BUCKLAND, M. K. What is a document? Journal of the American Society for Information Science, v.48, p. 804-809, 1997.

BURKE, P. Uma história social do conhecimento II: da Enciclopédia a Wikipédia. Rio de Janeiro: Zahar, 2012.

BURKE, P. Uma história social do conhecimento: de Gutenberg a Diderot. Rio de Janeiro: Zahar, 2003.

CRIPPA, G. Cassiodoro e as Institutiones Divinarum Litterarum como fonte histórica para a discussão sobre práticas bibliográficas e organização do conhecimento. Informação \& Informação, Londrina, v. 20, n. 2, p. 86-117, ago. 2015. Disponível em:

http://www.uel.br/revistas/uel/index.php/informacao/article/view/23126. Acesso em: 22 maio 2019.

CRIPPA, G. Memória: geografias culturais entre história e ciência da informação. In: MURGUIA MARANON, E. I. Memória: um lugar de diálogo para arquivos, bibliotecas e museus. São Carlos: Compacta, 2010. p. 79-110.

HAHN, T. B.; BUCKLAND, M. (Ed.). Historical studies in Information Science. Medford, NJ: Information Today, 1998. Disponível em: https://goo.gl/i3lm5C. Acesso em: 22 maio 2019.

LE COADIC, I.-F.. A ciência da informação. 2. ed. Brasília, DF: Briquet de Lemos, 2004.

MCCRANK, L. J. Historical Information Science: an emerging unidiscipline. Medford, NJ: Information Today, 2002. Disponível em: https://goo.gl/e7VAlm. Acesso em: 22 maio 2019.

MCCRANK, L. J. History, Archives, and Information Science. Annual Review of Information Science and Technology (ARIST), v. 30, p. 281-382, 1995.

OLIVEIRA, M. Origens e evolução da Ciência da Informação. In: OLIVEIRA, M. (Coord.). Ciência da Informação e Biblioteconomia: novos conteúdos e espaços de atuação. Belo Horizonte: Editora UFMG, 2005.

POMBO, O. A interdisciplinaridade: conceito, problemas e perspectivas. In: POMBO, O.; GUIMARÃES, H. M.; LEVY, T. A interdisciplinaridade: reflexão e experiência. Lisboa: Texto, 1993. p. 8-14. Disponível em:

http://webpages.fc.ul.pt/ ommartins/mathesis/interdisciplinaridade.pdf. Acesso em: 22 maio 2019.

PINHEIRO, L. V. R. Campo interdisciplinar da Ciência da Informação: fronteiras remotas e recentes. In: PINHEIRO, L. V. R. (Org.). Ciência da informação, ciências sociais e interdiscipli- 
naridade. Rio de Janeiro: IBICT, 1999. p. 155-182. Disponível em:

http://livroaberto.ibict.br/bitstream/1/1000/1/PINHEIRO.\%20Ci\%C3\%AAncia\%20da\%20Infor ma\%C3\%A7\%C3\%A30,\%20Ci\%C3\%AAncias\%20Sociais\%20e\%20Interdisciplinariedade.pdf.

Acesso em: 22 maio 2019.

RAYWARD, W. B. The history and historiography of Information Science: some reflections. In: HAHN, Trudi Bellardo; BUCKLAND, Michael (Ed.). Historical studies in Information Science. Medford, NJ: Information Today, 1998. Disponível em: https://goo.gl/i3lm5C. Acesso em: 02 jul. 2016.

RAYWARD, W. B. The origins of information science and the International Institute of Bibliography/International Federation for Information and Documentation (FID). Journal of the American Society for Information Science, v. 48, n. 4, p. 289-300, 1997.

SANTOS, A. P. L.; RODRIGUES, M. E. F. A interdisciplinaridade e a Ciência da Informação: algumas reflexões. Liinc em Revista, Rio de Janeiro, v. 9, n. 1, p. 335-349, maio 2013. Disponível em: http://revista.ibict.br/liinc/article/view/3377/2973. Acesso em: 22 mai. 2019.

SILVA, L. G.; SILVA, J. F. M. Análise da descrição bibliográfica do inventário da primeira biblioteca pública de São Paulo. Múltiplos Olhares em Ciência da Informação, v. 5, n. 1, p. 1-17, mar. 2015. Disponível em:

http://portaldeperiodicos.eci.ufmg.br/index.php/moci/article/view/2668/1734. Acesso em: 22 maio 2019.

SMIT, J.; TÁLAMO, M. F. G. M. Ciência da Informação: uma ciência moderna ou pósmoderna? In: LARA, M. L. G.; FUJINO, A.; NORONHA, D. P. (Org.). Informação e Contemporaneidade: perspectivas. Recife: Néctar, 2007. p. 27-46. Disponível em: http://www3.eca.usp.br/sites/default/files/form/ata/pos/ppgci/publicacoes\%20\%20informacaoContemporaniedade(1).pdf. Acesso em: 22 maio 2019.

WILLIAMS, Robert V. (Comp.). Bibliography of the history of Information Science and Technology, 1900-2012. 8. ed. 2012. Disponível em: https://www.asist.org/about/history-ofinformation-science/bibliography-of-information-science-and-technology/. Acesso em: 22 maio 2019. 